

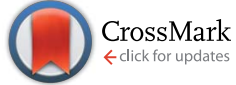

Cite this: Energy Environ. Sci., 2014, 7, 2925

Received 17th April 2014

Accepted 13th May 2014

DOI: $10.1039 / c 4 e e 01223 b$

www.rsc.org/ees

\section{Scalable, ambient atmosphere roll-to-roll manufacture of encapsulated large area, flexible organic tandem solar cell modules}

\author{
Thomas R. Andersen, ${ }^{a}$ Henrik F. Dam, ${ }^{a}$ Markus Hösel, ${ }^{a}$ Martin Helgesen, ${ }^{a}$ \\ Jon E. Carlé, ${ }^{a}$ Thue T. Larsen-Olsen, ${ }^{a}$ Suren A. Gevorgyan, ${ }^{a}$ Jens W. Andreasen, ${ }^{a}$ \\ Jens Adams, ${ }^{\text {bc }}$ Ning Li, ${ }^{\text {bc }}$ Florian Machui, ${ }^{\text {bc }}$ George D. Spyropoulos, ${ }^{\text {bc }}$ \\ Tayebeh Ameri, ${ }^{\text {bc }}$ Noëlla Lemaître, ${ }^{d}$ Mathilde Legros, ${ }^{d}$ Arnulf Scheel, ${ }^{e}$ Detlef Gaiser, ${ }^{e}$ \\ Kilian Kreul, ${ }^{f}$ Stephane Berny, ${ }^{9}$ Owen R. Lozman, ${ }^{9}$ Sirpa Nordman, ${ }^{\text {h }}$ Marja Välimäki, ${ }^{\text {h }}$ \\ Marja Vilkman, ${ }^{\text {h }}$ Roar. R. Søndergaard, ${ }^{a}$ Mikkel Jørgensen, ${ }^{a}$ Christoph J. Brabec ${ }^{\text {bc }}$ \\ and Frederik C. Krebs ${ }^{\star a}$
}

Inline printing and coating methods have been demonstrated to enable a high technical yield of fully roll-to-roll processed polymer tandem solar cell modules. We demonstrate generality by employing different material sets and also describe how the ink systems must be carefully co-developed in order to reach the ambitious objective of a fully printed and coated 14-layer flexible tandem solar cell stack. The roll-to-roll methodologies involved are flexographic printing, rotary screen printing, slot-die coating, X-ray scattering, electrical testing and UV-lamination. Their combination enables the manufacture of completely functional devices in exceptionally high yields. Critical to the ink and process development is a carefully chosen technology transfer to industry method where first a roll coater is employed enabling contactless stack build up, followed by a small roll-to-roll coater fitted to an X-ray machine enabling in situ studies of wet ink deposition and drying mechanisms, ultimately elucidating how a robust inline processed recombination layer is key to a high technical yield. Finally, the transfer to full roll-to-roll processing is demonstrated.

\section{Introduction}

The pinnacle of complexity for fully solution-processed organic electronics is represented by the organic tandem solar cell ${ }^{1}$ that

\footnotetext{
${ }^{a}$ Department of Energy Conversion and Storage, Technical University of Denmark, Frederiksborgvej 399, DK-4000 Roskilde, Denmark.E-mail: frkr@dtu.dk

${ }^{b}$ i-MEET (Institute Materials for Electronics and Energy Technology), FriedrichAlexander University Erlangen-Nürnberg, Martensstrasse 7, D-91058 Erlangen, Germany

'Bavarian Center for Applied Energy Research, Center for Renewable Energies, Haberstrasse 2a, D-91058 Erlangen, Germany

${ }^{d}$ CEA, LITEN, INES Campus, F-73375 Le Bourget du Lac, France

${ }^{e}$ Heraeus Precious Metals GmbH \& Co. KG, Electronic Materials Division, Chempark Leverkusen Bldg. B202, 51368 Leverkusen, Germany

${ }^{f}$ DELO Industrial Adhesives, DELO-Allee 1, 86949 Windach, Germany

${ }^{g}$ Merck Chemicals Ltd., Chilworth Technical Centre, University Parkway, Southampton, SO16 $7 Q D$, UK

${ }^{h}$ VTT Technical research center of Finland, P.O. Box 1000, FI-02044 VTT, Finland
}

\section{Broader context}

The polymer solar cell is one of the most scientifically reported energy technologies not only due to the promises of being an exceptionally low environmental impact technology on a massive scale, but also because it can be realized in a myriad of ways and can be made subject to a near infinite level of variation. The enormous complexity is reflected both in the ease with which they can be made and also in the difficulty with which they are made efficient. In spite of the enormous number of reports $(>10000)$ there is still no standard procedure for realizing high efficiency devices beyond magic and luck. Efforts in scaling such that generic methods are available is key to reaching this level and significant research is needed within this area if the technology is to become viable outside academia. The highest efficiency for the polymer solar cell is possible through the multi-junction architecture where two or more junctions are stacked on top of each other, thus representing a task that is both difficult and challenging, but also potentially rewarding if it can be realized. We show how fully scalable tandem OPV modules can be prepared using full roll-to-roll processing and we also illustrate what equipment is needed to carry out the experiments and highlight areas that could facilitate further development of the technology, especially with respect to materials development and materials properties.

requires a large selection of materials, careful formulation into inks and solvent systems compatible with the required combination of fast printing/coating techniques that are included in the process along with challenging film thickness and quality control. The motivation is clearly the desire to tap into the potentially higher power conversion efficiency that multi-junction solar cells have to offer. At the same time it is assumed that the added complexity that multi-junction solar cells also imply can be overcome easily. The power conversion efficiency of laboratory-scale polymer tandem solar cell devices reportedly exceeds $10 \%$ (ref. 2 and 3 ) and has been predicted to have technical potential in the range of $15-25 \%{ }^{4,5}$ The scaled efficiency that can currently be reached with fully roll-to-roll processed single junction polymer solar cells, that are true to the art and vision of high speed manufacture without any discrete steps, is significantly lower than the record single junction 
laboratory devices. The best reported power conversion efficiency for fully printed, flexible single junctions that do not comprise indium-tin-oxide (ITO), vacuum or discrete processing steps is $3.5 \%$ over an area of $1 \mathrm{~cm}^{2}{ }^{6}$ There is a significant gap between the power conversion efficiency for single laboratory observations on very small active areas and the average performance of large area flexible devices that are packaged into a final form. ${ }^{7,8}$ The former is of course representative of the potential of the technology while the latter is what can be practically achieved with the current materials and methods. This was recently epitomized in a large study that encompassed a compilation of all data reported for polymer solar cells (around 12000 datasets from 9000 scientific reports). ${ }^{9}$ This study highlighted a large spread in data and a significant gap between the values found at the outskirts of the Poisson type distribution and the average values that most probably represents what can be achieved in practice. The study also raised the important question of how to scale the technology to higher efficiencies if at all possible. One conclusion could be that the topic of large area processing methods must be addressed with significant research intensity if the potential of the technology is to be realized. The advantages of the roll-to-roll solution processed polymer solar cells are well demonstrated in terms of volume, robustness and reproducibility. ${ }^{10,11}$ Even a simple laboratory roll-to-roll machine enables the robust manufacture of many kilometers of foil with solar cell modules over a few hours, clearly demonstrating the edge that polymer solar cells have to offer over all other known energy technologies: ultra-high speed manufacture of enormous areas of solar cells that embody very little energy and materials. ${ }^{12,13}$ Existing single junction polymer solar cells have already been demonstrated to outperform all other energy technologies with respect to embodied energy, materials use, recyclability, installation speed and energy pay-back time, and it is clear that a higher performance would further increase the appeal of this technology as long as it does not compromise the benefits that have already been realized. ${ }^{13-15}$ The tandem structure potentially gives access to a higher performance than the single junction at the expense of extra processing steps and material input. Besides the central question of whether it is at all possible, it is imperative to establish nearly the same technical yield as for the single junctions.

Here, we present the first fully roll-to-roll processed flexible polymer tandem solar cell modules with a large area. The modules were prepared using a generic process employing a series of roll-toroll processing techniques that were carried out under ordinary laboratory conditions in an ambient atmosphere (i.e. no clean room). We only employed wet processing (i.e. no vacuum steps), additive printing and coating methods (i.e. no lithographic or subtractive techniques) throughout the module manufacture. We demonstrated that inline coating of the intermediate layer is critical for the success and enables a high technical yield.

\section{Experimental}

\subsection{Materials}

Several substrate materials were employed. Melinex ST506 (130 micron thick polyester), 60 micron and 40 micron thick polyester barrier materials from Amcor, respectively, with and without a UV-filter having an optical cut-off of $390 \mathrm{~nm}$ were used. The barrier materials had an oxygen transmission rate of $0.01 \mathrm{~cm}^{3} \mathrm{~m}^{-2}$ per day and a water vapor transmission rate of $0.04 \mathrm{~g} \mathrm{~m}^{-2}$ per day. Front silver was PFI-722 from PCHEM; three different PEDOT:PSS formulations were used (Heraeus PH1000, AI 4083 and F010 diluted with isopropanol in a ratio described under R2R processing); active materials were the wide band gap semiconductors MH301 and Polymer Generation 2.1 and low band gap semiconductors were MH306 and Polymer Generation 2.2. $\mathrm{MH} 301 / \mathrm{MH} 306$ (ref. 16-18) and $\mathrm{PFN}^{19}$ were prepared according to literature procedures. PFN was dissolved in methanol at a concentration of $0.4 \mathrm{mg} \mathrm{mL}^{-1}$. Polymer Generation 2.1/Polymer Generation 2.2 and the acceptor PCBM $\left(\mathrm{C}_{60^{-}}\right.$ fullerene) were supplied by Merck Chemicals. The solutions of the absorbers were prepared by mixing with PCBM in the following ratios: MH301 : PCBM $\left(5 \mathrm{mg} \mathrm{mL}^{-1}: 10 \mathrm{mg} \mathrm{mL}^{-1}\right)$ in chlorobenzene, MH306 : PCBM $\left(8 \mathrm{mg} \mathrm{mL}^{-1}: 13.5 \mathrm{mg} \mathrm{mL}^{-1}\right)$ in chloroform, Polymer Generation $2.1:$ PCBM $\left(7 \mathrm{mg} \mathrm{mL}^{-1}: 18\right.$ $\left.\mathrm{mg} \mathrm{mL} \mathrm{m}^{-1}\right)$ in $o$-xylene : tetralin $(90: 10 \mathrm{v} / \mathrm{v})$, and Polymer Generation 2.2 : PCBM $\left(14 \mathrm{mg} \mathrm{mL}^{-1}: 21 \mathrm{mg} \mathrm{mL}^{-1}\right)$ in chloroform; ZnO nanoparticles were prepared according to the literature $^{20}$ and dispersed in acetone with a concentration of $56 \mathrm{mg}$ $\mathrm{mL}^{-1}$. The back silver was a screen printing formulation from Dupont (5025) and the carbon was a screen printing formulation from Acheson (PF407). The adhesives employed for encapsulation were from DELO (LP655, VE110484, LP612). The general substrate comprising any of the polyester materials above was used with a printed front electrode combination of silver grid, PEDOT:PSS and ZnO known as the Flextrode. ${ }^{7}$

\subsection{Mini-roll coating}

The general procedure for coating was conducted as presented previously $y^{21-23}$ on a mini-roll coater developed by us ${ }^{21,22}$ which is now commercially available. ${ }^{22}$ The procedure was similar to the previous tandem report with small variations as noted here. (1) The high-bandgap sub-cell was coated with a theoretical dry thickness of $180-220 \mathrm{~nm}$ depending on the polymer, (2) the compatible PEDOT:PSS F010 layer was coated with a wet thickness of $8 \mu \mathrm{m}$, (3) the PEDOT:PSS AI 4083 hole selective layer at $23 \mu \mathrm{m}$ wet layer thickness, (4) zinc oxide had a wet thickness of $5 \mu \mathrm{m}$, (5) the low-bandgap sub-cell was coated to obtain a dry thickness of $300-350 \mathrm{~nm}$, (6) the compatible PEDOT:PSS F010 layer was coated with a wet thickness of $8 \mu \mathrm{m}$, (7) the PEDOT:PSS AI 4083 hole selective layer at $23 \mu \mathrm{m}$ wet layer thickness, (8) the PEDOT:PSS F010 top electrode was coated with a wet thickness of $38 \mu \mathrm{m}$, and (9) the silver top electrode was flexographically printed with a web speed of $1.3 \mathrm{~m} \mathrm{~min}^{-1}$.

\subsection{Roll-to-roll GISAXS}

Grazing incidence small angle X-ray scattering model studies were carried out on a custom SAXS setup, employing a rotating anode source, operating at $40 \mathrm{kV}, 40 \mathrm{~mA}$, with a focused, monochromated (1.5418 $\AA$ wavelength) beam, collimated to $1 \mathrm{~mm}$ beam size on the sample. The X-ray incidence angle was $0.35^{\circ}$. Data were acquired using a $2 \mathrm{D}$ delay line gas proportional 
detector with $29 \times 100$ s exposure and analyzed for the presence of the P3HT stacking peak as an indication of the structural integrity of the stack. Layers were coated at a speed of $0.5 \mathrm{~m}$ $\min ^{-1}$ with identical wet layer thicknesses to the full scale rollto-roll coating described in the roll-to-roll processing section.

\subsection{Roll-to-roll equipment used}

Four roll-to-roll processing machines were employed to carry out the complete process: (1) a R2R inline machine (305 mm web width) comprising an unwinder, an edge guide, a web cleaner, a corona treater, an input nip, a flexographic unit, a slot-die unit $\# 1$, an oven $\# 1$, a rotary screen printer, a slot-die unit $\# 2$, an oven $\# 2$, an output nip, a barcode writer and a rewinder. The machine has 3 tension zones. (2) A R2R testing machine (510 mm web width) comprising a testing unit, a nip and a rewinder. (3) A R2R UV-laminator comprising an unwinder, a dancing roller system for tension control, a corona treater, an edge-guide, a flexographic unit, a lamination nip, a laminate (tandem solar cell) unwinder, a high power UV lamp (5 $\mathrm{kW}), 300 \mathrm{~mm} \times 400 \mathrm{~mm}$ high power LED curing lamps, an output nip and a rewinder. (4) A R2R laser cutting machine for finally cutting out the completed modules. Contacts were made by punching snap connectors through the area printed with graphite.

\subsection{Roll-to-roll processing}

The Flextrode was prepared as described in the literature ${ }^{7}$ with the exception that the processing speed was changed for the front silver grid $\left(20 \mathrm{~m} \mathrm{~min}^{-1}\right)$ and PEDOT:PSS $\left(20 \mathrm{~m} \mathrm{~min}^{-1}\right)$. The thickness of the front PEDOT:PSS layer (PH1000) was also halved. The absorber layers were slot die coated using a die with a 16 stripe mask and a meniscus guide. MH301:PCBM inks were coated at an oven temperature of $140{ }^{\circ} \mathrm{C}$, a web speed of $1.5 \mathrm{~m}$ $\mathrm{min}^{-1}$ and a wet thickness of 12.5 micron; MH306:PCBM inks were coated at an oven temperature of $20^{\circ} \mathrm{C}$, a web speed of 1.2 $\mathrm{m} \min ^{-1}$ and a wet thickness of 10.4 micron; Polymer Generation 2.1:PCBM inks were coated at an oven temperature of $60^{\circ} \mathrm{C}$, a web speed of $1.8 \mathrm{~m} \mathrm{~min}^{-1}$ and a wet thickness of 10.4 micron; Polymer Generation 2.2:PCBM inks were coated at an oven temperature of $20{ }^{\circ} \mathrm{C}$, a web speed of $1.2 \mathrm{~m} \mathrm{~min}^{-1}$ and a wet thickness of 10.4 micron. The PFN ink was coated at an oven temperature of $60{ }^{\circ} \mathrm{C}$, a web speed of $2.4 \mathrm{~m} \mathrm{~min}^{-1}$ and a wet thickness of 7.8 micron. In the inline experiment for the intermediate layer, the web speed was $1 \mathrm{~m} \mathrm{~min}^{-1}$. The PEDOT:PSS ink (AI 4083 diluted with isopropanol 1:2 by volume) was dried at an oven temperature of $40{ }^{\circ} \mathrm{C}$ with a wet thickness of 25 micron. The $\mathrm{ZnO}$ ink was dried at $60{ }^{\circ} \mathrm{C}$ with a wet thickness of 6.25 micron. The back PEDOT:PSS-PEDOT:PSS bilayer was also coated using inline processing. The first PEDOT:PSS ink (AI 4083 diluted with isopropanol 1:1 by volume) was dried at $20{ }^{\circ} \mathrm{C}$ with a wet thickness of 25 micron and the second PEDOT:PSS layer was dried at $60{ }^{\circ} \mathrm{C}$ with a wet thickness of 37 micron. The silver back electrode was rotary screen printed at a web speed of $2 \mathrm{~m} \mathrm{~min}^{-1}$ and dried at $120{ }^{\circ} \mathrm{C}$. The carbon contacts were rotary screen printed at a web speed of $2 \mathrm{~m} \mathrm{~min}^{-1}$ and dried at $120^{\circ} \mathrm{C}$. Devices were roll-to-roll tested at a web speed of $0.25 \mathrm{~m} \mathrm{~min}^{-1}$. UV-lamination was carried out using corona treatment of the protective foil (not on the solar cell) using a power setting of $2 \mathrm{~kW}$ on the high power UV lamp and $36 \mathrm{~W}$ optical output from the LED lamp array. The web speed was $1.5 \mathrm{~m} \mathrm{~min}^{-1}$ and the adhesives tested VE110484 and LP655 were the best and about equal in practicality, use and performance. Laser cutting was carried out using a roll-to-roll laser cutter comprising a $90 \mathrm{~W} \mathrm{CO}_{2}$ laser. The linear cutting speed of the laser was $4 \mathrm{~m} \mathrm{~min}^{-1}$.

\subsection{Device performance and stability testing}

$I-V$ curves were recorded under a Steuernagel K1200 metalhalide lamp with a neoceram filter using a Keithley 2400 source meter. The intensity was calibrated using a high temperature pyranometer from Kipp \& Zonen. The accurate determination of sample performance was carried out at CLOP (the Characterization Laboratory for Organic Photovoltaics) using SRC (standard reporting conditions $1000 \mathrm{~W} \mathrm{~m} \mathrm{~m}^{-2}, 25{ }^{\circ} \mathrm{C}$ ). First, the external quantum efficiency of the samples was measured by individual electrical and light biasing of each junction in the tandem stack followed by determination of the total spectral response of the complete device. The data were then used to calculate the spectral mismatch between the samples and the calibration photodiode (with KG5 filter) used for the calibration of the solar simulator (with A class light spectrum). During the $I-V$ scanning the samples were kept at $25 \pm 1{ }^{\circ} \mathrm{C}$ using a cooling stage. The values reported under SRC in this study contain an error of less than $2 \%$.

\section{Results and discussion}

\subsection{Transfer from lab to fab}

Fig. 1 shows the layer stack employed for the fully roll-to-roll processed flexible polymer tandem cell along with the materials employed in each layer. The process starts with transparent polyester foil which may comprise barrier properties onto which the first slanted comb silver electrode is printed using flexographic printing at a high speed $\left(20 \mathrm{~m} \mathrm{~min}^{-1}\right)$. Simultaneously a barcode is printed enabling unique identification of each printed motif. This transcends the entire process and implies that each individual cell in a module can be identified throughout the process and electrical data measured in the end can be linked back to every step of the process for every printed motif. Fig. 1 also shows the outline of the foil including how the modules are laid out on the foil. The photograph shows a tandem device from the front side based on the two active materials MH301 (red colour) and MH306 (green colour) that are slightly offset with respect to each other and the two colours are clearly visible in the zoom-in. The challenge in realization of a tandem stack for a finally packaged flexible polymer tandem solar cell module that has been prepared entirely by sequential wet processing of all layers should not be underestimated. The current stack involves 14 subsequent roll-to-roll processing steps and is representative of what one would require to manufacture this on a large industrial scale. We made use of our extensive experience with state-of-the-art roll and roll-to-roll 


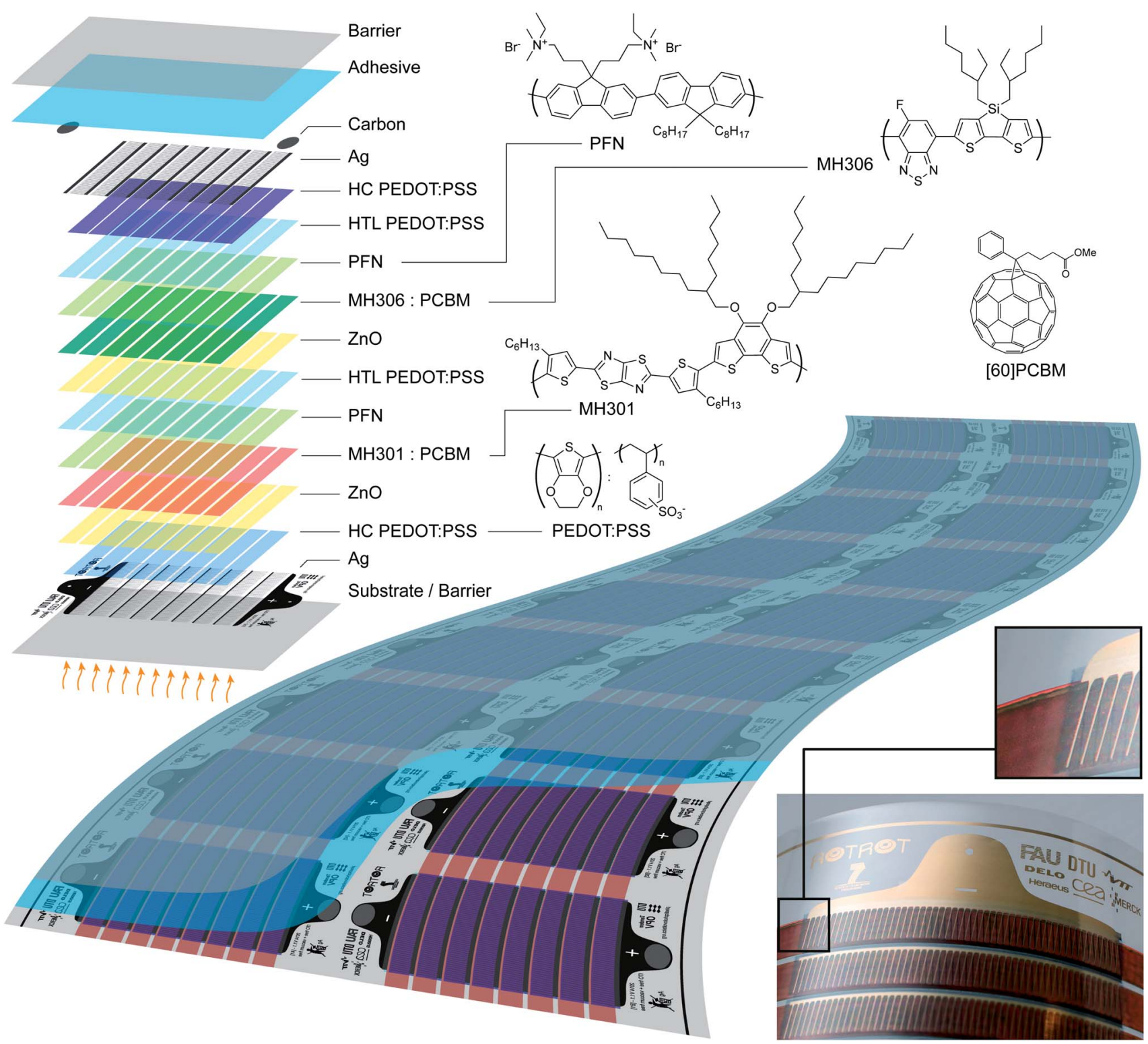

Fig. 1 The complete 14-layer tandem stack (upper left) along with structural formulae and names for the different materials involved (top right). The outline of the printed web is shown (middle) along with an actual photograph of a module (lower right). In the close-up photograph, the differently coloured active materials (red colour from MH301, green colour from MH306 and blue colour from PEDOT:PSS) are seen representing the wide band gap and low band gap semiconductor junctions and the hole transport layer.

processing. Some of the machinery that we employed is shown in Fig. 2 where we highlight the use of a roll-coating machine ${ }^{21,22}$ that is sufficiently removed from the traditional processing methods such as spin coating and vacuum evaporation while being significantly closer to full roll-to-roll processing to facilitate technology transfer.

The mini-roll coater has several advantages and makes it possible to eliminate potential sources of error from the inevitable boundary conditions that full roll-to-roll processing implies. The mini-roll coater allows for the preparation of multilayer stacks: (1) without having to touch the surface of the foil, (2) with zero web tension, (3) with a very large bending radius during the entire experiment, and (4) the foil is not subject to flexing during the entire experiment as it stays on the roll (drum). Perhaps the most central question is if one of the layers would be sensitive to the surface being touched during the processing. The touching of the printed (but dried) surface is impossible to avoid in ordinary R2R processing where surfaces come into contact with the rollers when transported through the machine and even though it is possible to develop systems without surface contact using air rollers the eventual rewinding of foil on a roll will result in the front and back of a foil touching. The mini-roll coater was designed to enable completion of a full process (with any number of layers) without bringing the surface into contact with anything else but the wet ink of the subsequently processed layer. In the ultimate case this is deemed impractical and processes must be robust enough to ensure that the surface is brought into contact with 


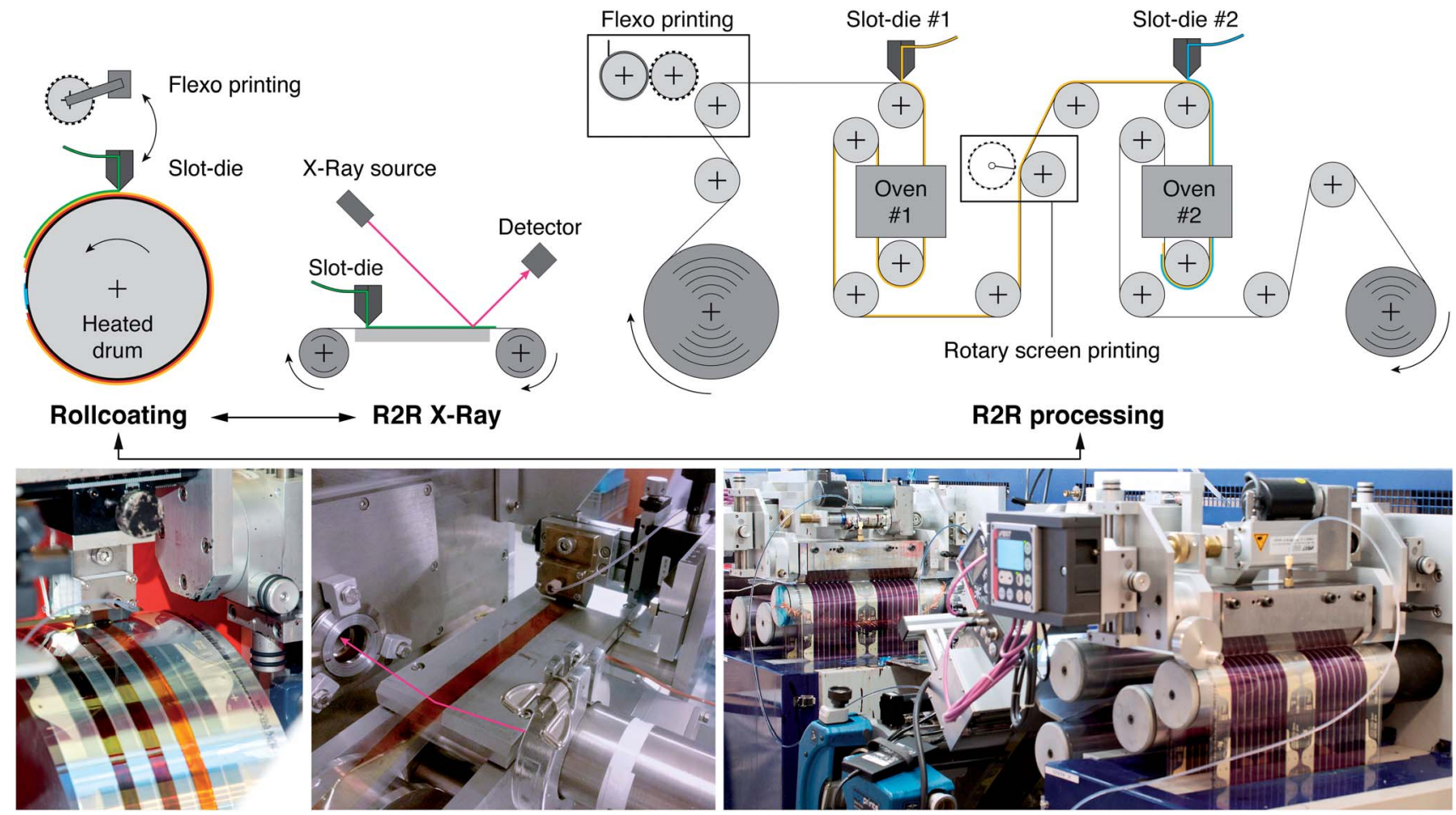

Fig. 2 Roll-to-roll and roll processing methods shown schematically (above) and corresponding photographs during coating operation (below). The junction and process development by sequential stacking of all layers without making surface contact using a roll coater (left) along with the small roll-to-roll X-ray machine (middle) where coating was carried out while the wet, drying and dry film could be probed using Grazing Incidence Small Angle X-ray Scattering (GISAXS). Inline coating using two fully automated slot-die coating stations and two ovens are shown (right) while the intermediate layer comprising PEDOT:PSS and ZnO was prepared.

the surroundings. During development and scientific studies however the mini-roll coater efficiently excludes this and many other potential sources of error. We initially succeeded in realizing functional tandem devices ${ }^{23}$ and also demonstrated that perfect stacks could be realized based on high resolution X-ray ptychography ${ }^{24}$ on the mini-roll coater. We however failed in transferring the process to a full roll-to-roll coating setting.

\subsection{Roll-to-roll X-ray scattering}

By careful analysis using a small model roll-to-roll coater that can be mounted in front of an X-ray scattering instrument ${ }^{25}$ (shown in Fig. 2 with data in Fig. $3 \mathrm{f}-\mathrm{h}$ ) we could study the structural evolution in an already printed/coated layer as a function of wet layer deposition on top. The most suited technique was found to be Grazing Incidence Small Angle X-ray Scattering (GISAXS) where structural information from the lamellar stacking was used as a marker for the integrity of the layer(s) already present. Model studies involving a layer of P3HT:PCBM were used when probing the wet processing on top of it and we found that the components of the intermediate layer (PFN, PEDOT:PSS and $\mathrm{ZnO}$ ) processed from respectively methanol, water/isopropanol and acetone could be coated easily on top of the active layer whereas the processing of the second active layer from an organic solvent such as xylene, chlorobenzene, dichlorobenzene or chloroform would lead to destruction of the already coated layer. Upon drying, the structure was of course re-observed, but the sequential layer stack and the integrity of the individual layers were compromised as evidenced by cracks in the intermediate layer and of course the lack of functionality as a tandem solar cell. We employed the roll-to-roll X-ray machine to identify the solvents and coating conditions required for robustness of the process. Most notably we found a stark difference between the solvent resistance of the intermediate layer when processed using rollto-roll processing of each layer in discrete steps and the coating of the intermediate layer in the same machine passage using inline coating as shown in Fig. 2.

\subsection{Inline processing for high technical yield and tandem operation}

The difference in the technical yield is very convincing and we employed several material combinations and found the inline processing to consistently enable robust manufacture while discrete processing did not enable us to prepare a single module where all eight cells of each module were tandem junctions. Discrete processing allowed for tandem cell processing and we found modules where several of the adjacent cells were tandem junctions. It could perhaps be expected that inline processing (i.e. processing where several layers are added during the same passage of foil through the machine) has an advantage over discrete processing, however the level of importance is unexpected. In terms of performance the accurate 

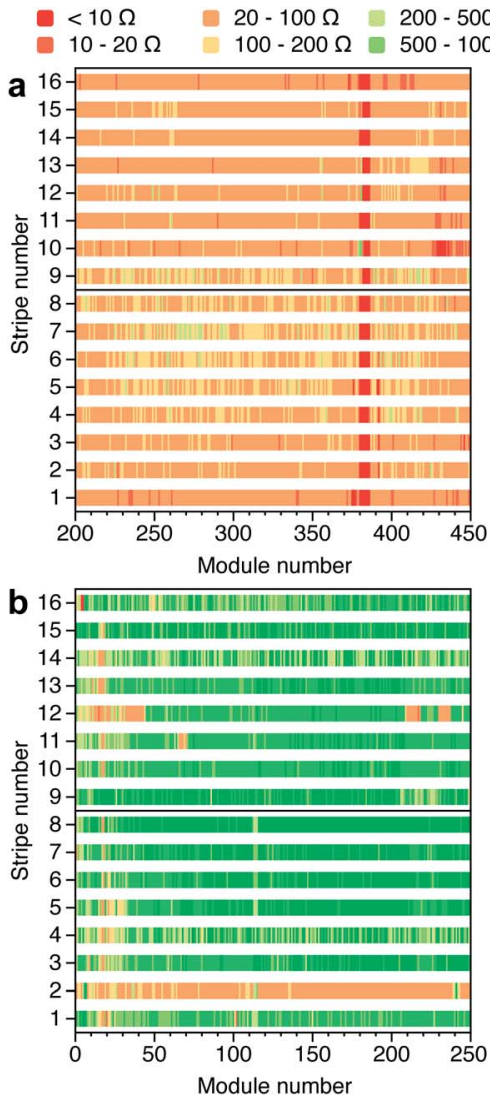
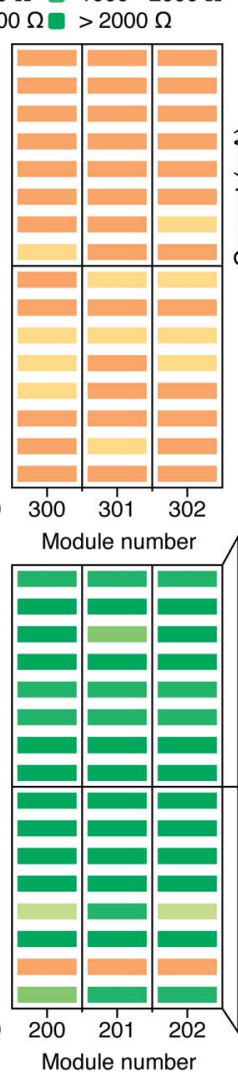

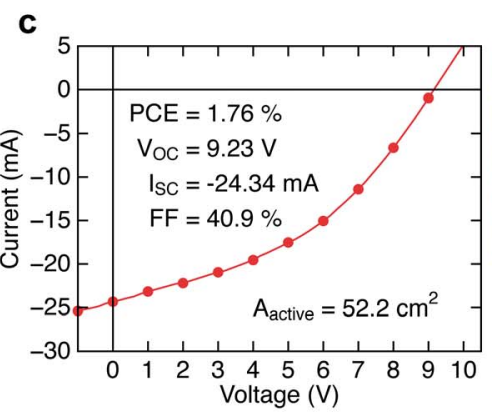

$\mathbf{f}$

d

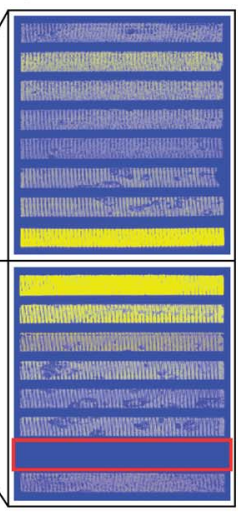

e

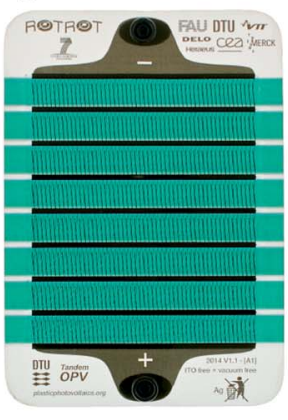

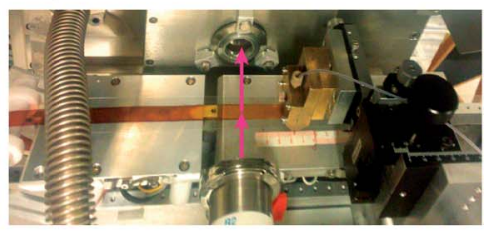

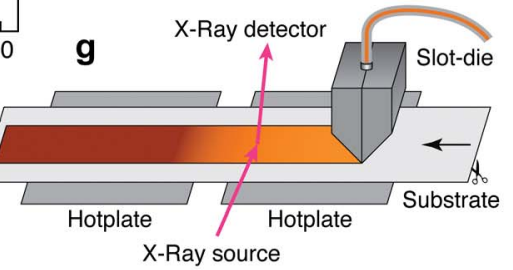

h

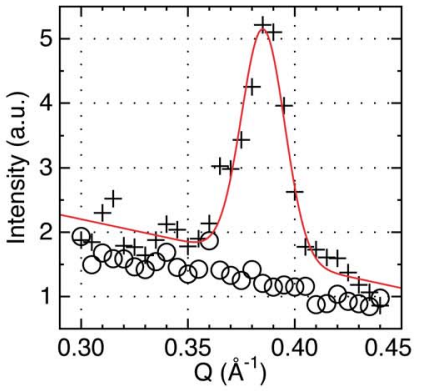

Fig. 3 Technical yield for two roll-to-roll processing runs. Discrete processing was employed in (a) and inline processing was employed in (b). A red colour is indicative of a non-solar junction (shorted), yellow/orange is typical of a single junction behavior and light green/dark green is typical of fully functional tandem junctions. No fully functional modules could be obtained through discrete processing while some of the junctions within each module exhibited tandem behavior. This could be verified by LBIC in (d) where the missing stripe 2 for the inline processed modules could be clearly identified (red box). Inline processing enabled the technical yield to be very high with essentially all modules being tandem devices with a typical open circuit voltage $>9 \mathrm{~V}$ as shown in (c) for an 8 cell module shown in (e) using a commercially available material set for the active layers (Polymer Generation 2.1 and Polymer Generation 2.2). The R2R X-ray experiment while coating a P3HT:PCBM layer is shown in (f) where the lighter orange colour is the wet film. The experiment on the photograph is shown schematically in (g). R2R X-ray data for the (100) peak of P3HT:PCBM films are shown in (h) for the case of a robust intermediate layer (crosses) and an imperfect intermediate layer that allows the solvent to penetrate through the film and dissolve it (open circles) whereby the (100) peak disappears.

efficiency measurements under standard reporting conditions (see the Methods section) revealed a certified PCE value of $1.76 \%$ over an active area of $52.2 \mathrm{~cm}^{2}$ for a module with eight tandem cells in series (Fig. 3c). This performance is comparable with single junction modules prepared using essentially the same module layout (freeOPV ${ }^{12}$ ) and underlines the need for further development both within materials and interfaces and also within processing. It should be stressed that these devices are fully printed and coated without vacuum steps and as such constitute a fully scalable technology provided that higher efficiency levels can be reached.

\subsection{Flexible tandem OPV modules}

The major step forward that we present here is that it is in fact possible to manufacture flexible large area tandem OPV modules under ambient conditions (no clean room) using only printing and coating methods in a layer stack that comprises quite a significant number of chemically different layers. The entire tandem stack comprises 14 wet processed layers and involves a number of different processing methods. In this work we have sought to demonstrate a process that is fully scalable and without limitations and have reached this challenging goal. The active area of the tandem modules $\left(52.2 \mathrm{~cm}^{2}\right)$ accurately determined using the combination of LBIC and a precision electronic caliper can be qualified as "large" underscoring that it is possible to robustly prepare such multi-layer stacks using wet processing over large areas without special precaution. Inline processing enabled us to reach a high technical yield as shown in Fig. $3 \mathrm{~b}$ where the electrical data for all junctions are shown for 25 meters of processed foil (500 modules $\sim 4000$ tandem junctions). In Fig. $3 \mathrm{~b}$ it can be seen that aside from the beginning and end of the foil all the modules are functional. In one of the processing runs there was a defect in one of the junctions that propagated through the entire run. This was also clearly seen in LBIC images ${ }^{26}$ for module 200 (each module number comprises two eight cell tandem modules). On the plot (Fig. 3a and b) light green to dark green cells are functional 
a

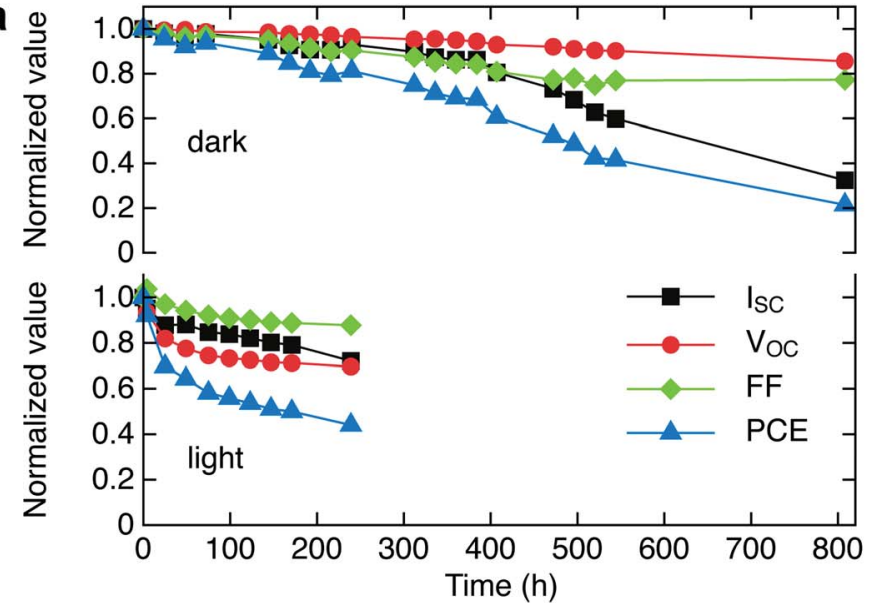

b

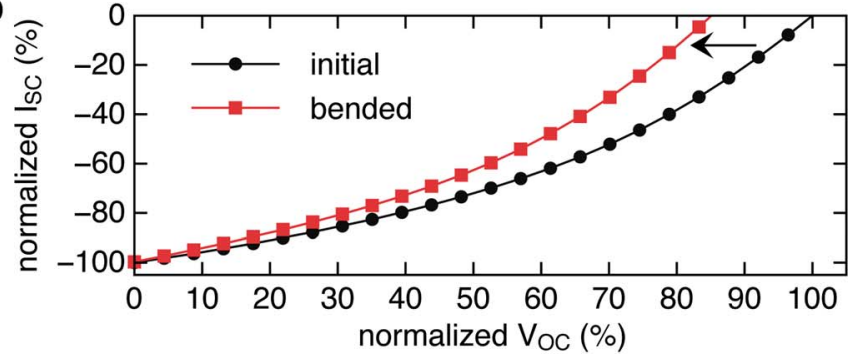

C

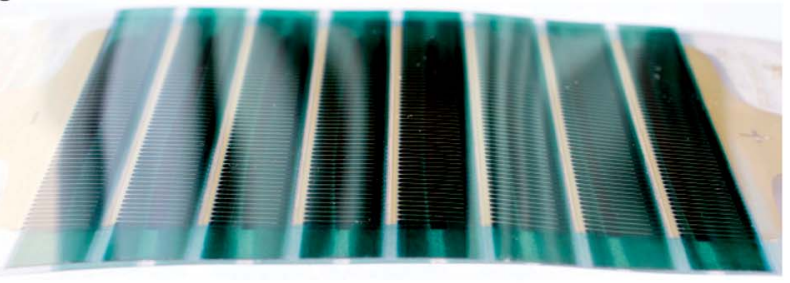

d

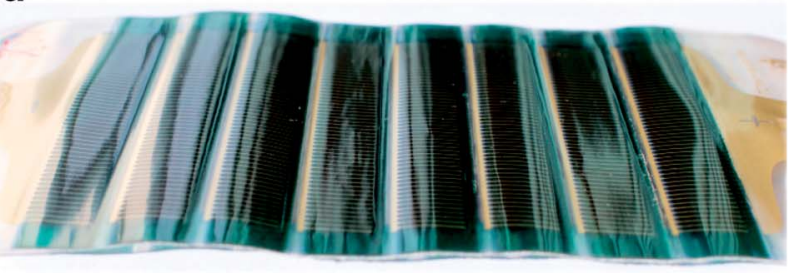

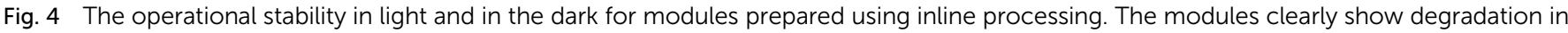

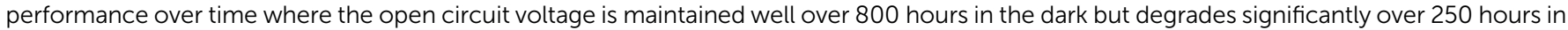

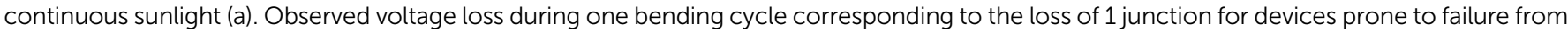

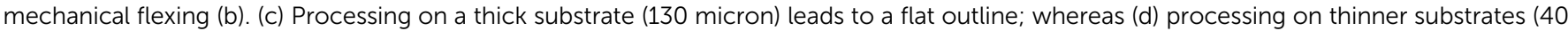
and 60 micron) leads to buckling where it is shown for a 60 micron substrate.

tandem junctions. In the case of discrete processing (Fig. 3a), the majority of the junctions did not operate as tandem junctions while some tandem junctions were successfully prepared and confirmed to be tandem junctions by extraction and testing. In the case of discrete processing (Fig. 3a) the technical yield of tandem junctions for a full run (4000 junctions, 500 modules) was in the range of $11-28.8 \%$. In contrast inline processing (Fig. $3 \mathrm{~b}$ ) gave access to much higher technical yields in the range of $88.8-96.9 \%$ for a full run (4000 junctions, 500 modules). The advantage of the processing system is that every cell on the roll is uniquely identifiable and electrical data are recorded for each cell before packaging by UV-lamination. We were also able to ship these devices to all the laboratories participating in this development and found agreement on both performance and operational stability under dark storage (ISOSD-1) ${ }^{27}$ and light soaking (ISOS-L-1). ${ }^{27}$ The shelf life demonstrates maintenance of open circuit voltage over 800 hours while PCE degrades due to loss of mainly $I_{\mathrm{sc}}$ (Fig. 4). This demonstrates that the tandem junction is stable over some time and at least in this first version stable enough to warrant further development. The loss in FF and $I_{\mathrm{sc}}$ is likely to be caused by the gradual trap formation in $\mathrm{ZnO}$, which is difficult to anneal out in a dark storage experiment with limited light soaking during the intermittent testing. Under light, all parameters degrade fast initially but do seem to stabilize to a constant decay after around 150 hours where the FF demonstrates the most stable behaviour.

\section{Conclusions}

Overall these promising results certainly warrant further material, process and device development and even if the performance of the tandem devices prepared does not progress beyond single junctions the technical development goes beyond speculation in the possibility of wet processing of organic tandem solar cells. We confirm that it is possible to carry out these experiments under simple conditions with high technical yield and it is possible to prepare an enormous number of modules in a short time using a fully scalable process. The data acquired have allowed for a detailed cost analysis ${ }^{28}$ enabling comparison with other analysis ${ }^{29}$ and underline the impact that process development can have. Most particularly the specific development of materials for a particular process such as this could allow us to tap into the advantages that tandem polymer solar cells do have to offer. It is however likely that the scientific thrust should be with the final form and processing methods in mind and not as it has been until now with a blind focus on high performance in an often unrealistic and not scalable setting. It is also very likely that the active materials and inks will have to be developed specifically with the thermomechanical properties of the multi-layer structure in mind. The complex multi-layer structure with different thermal expansion coefficients and moduli for the individual layers and different adhesion energies at each interface are likely to present an enormous challenge for the manufacture of a robust flexible 
tandem organic solar cell. ${ }^{\mathbf{3 0}, 31}$ This was clearly observed when we processed the modules on substrates with different layer thicknesses. We could successfully process functional tandem devices on all three substrate thicknesses when employing a mini-roll coater where there is no web tension and a very large bending radius. During roll-to-roll processing of the foils the largest strains and compressions were observed for the thickest substrate $(0.27 \%$ strain, $0.25 \%$ compression) leading to the conclusion that strain and compression must be minimized as should roller passage. This will enable a robust and high yield ambient tandem OPV process together with materials development towards high elasticity and interface adhesion. ${ }^{31}$ Studies on thermo-mechanical properties are the least explored in this context while there are of course also several other aspects, some of which we have addressed in this work but far from exhaustively. Most importantly the control of film thickness and especially the evenness of the dry films for the multi-layer stack through proper ink design. This involves control of viscosity, ink stability over time, ink rheology during deposition, ink rheology during drying (i.e. heating and up-concentration of solutes in the wet film), wetting behaviour during deposition and drying, control over morphology formation and of course it must all work in air.

\section{Acknowledgements}

This work has received financial support from the European Commission as part of the Framework 7 ICT 2009 collaborative project ROTROT (grant no. 288565), Eurotech Universities Alliance project "Interface science for photovoltaics (ISPV)", European Research Infrastructure (SOPHIA) and European Energy Research Alliance (EERA) are acknowledged for the support. CJB acknowledges funding from the Excellence Cluster of Advanced Materials (EAM) and the Soltec Initiative "Solar goes Hybrid" from the Bavarian Ministry of Science and Education. This work has also been supported by the Danish National Research Foundation. Partial financial support was also received from the Danish Council for Independent Research, Technology and Production Sciences (project no. 11-116864), the Danish Ministry of Science, Innovation and Higher Education under a Sapere Aude Top Scientist grant (no. DFF - 1335-00037A) and an Elite Scientist grant (no. 11-116028).

\section{Notes and references}

1 T. Ameri, G. Dennler, C. Lungenschmied and C. J. Brabec, Energy Environ. Sci., 2009, 2, 347-363.

2 J. You, L. Dou, K. Yoshimura, T. Kato, K. Ohya, T. Moriarty, K. Emery, C. C. Chen, J. Gao, G. Li and Y. Yang, Nat. Commun., 2013, 4, 1446-1455.

3 J. You, C. C. Chen, Z. Hong, K. Yoshimura, K. Ohya, R. Xu, S. Ye, J. Gao, G. Li and Y. Yang, Adv. Mater., 2013, 20, 3973-3978.

4 G. Dennler, M. C. Scharber, T. Ameri, P. Denk, K. Forberich, C. Waldauf and C. J. Brabec, Adv. Mater., 2008, 20, 579-583. 5 N. Li, D. Baran, K. Forberich, F. Machui, T. Ameri, M. Turbiez, M. Carrasco-Orozco, M. Dress, A. Facchetti,
F. C. Krebs and C. J. Brabec, Energy Environ. Sci., 2013, 6, 3407-3413.

6 M. Helgesen, J. E. Carlé and F. C. Krebs, Adv. Energy Mater., 2013, 3, 1664-1669.

7 M. Hösel, R. R. Søndergaard, M. Jørgensen and F. C. Krebs, Energy Technol., 2013, 1, 102-107.

8 P. Sommer-Larsen, M. Jørgensen, R. R. Søndergaard, M. Hösel and F. C. Krebs, Energy Technol., 2013, 1, 15-19.

9 M. Jørgensen, J. E. Carlé, R. R. Søndergaard, M. Lauritzen, N. A. Dagnæs-Hansen, S. L. Byskov, T. R. Andersen, T. T. Larsen-Olsen, A. P. L. Böttiger, B. Andreasen, L. Fu, L. Zuo, Y. Liu, E. Bundgaard, X. Zhan, H. Chen and F. C. Krebs, Sol. Energy Mater. Sol. Cells, 2013, 119, 84-93.

10 R. Søndergaard, M. Hösel, D. Angmo, T. T. Larsen-Olsen and

F. C. Krebs, Mater. Today, 2012, 15, 36-49.

11 F. C. Krebs, Sol. Energy Mater. Sol. Cells, 2009, 93, 394-412. 12 F. C. Krebs, M. Hösel, M. Corazza, B. Roth, M. V. Madsen, S. A. Gevorgyan, R. R. Søndergaard, D. Karg and M. Jørgensen, Energy Technol., 2013, 1, 378-381.

13 F. C. Krebs, N. Espinosa, M. Hösel, R. R. Søndergaard and M. Jørgensen, Adv. Mater., 2014, 26, 29-39.

14 N. Espinosa, M. Hösel, M. Jørgensen and F. C. Krebs, Energy Environ. Sci., 2014, 7, 855-866.

15 R. R. Søndergaard, N. Espinosa, M. Jørgensen and F. C. Krebs, Energy Environ. Sci., 2014, 7, 1006-1012.

16 J. E. Carlé, M. Helgesen, M. V. Madsen, E. Bundgaard and F. C. Krebs, J. Mater. Chem. C, 2014, 2, 1290-1297.

17 T. S. van der Poll, J. A. Love, T. Q. Nquyen and G. C. Bazan, Adv. Mater., 2012, 24, 3646-3649.

18 J. Hou, H. Y. Chen, S. Zhang, G. Li and Y. Yang, J. Am. Chem. Soc., 2008, 130, 16144-16145.

19 F. Huang, H. Wu, D. Wang, W. Yang and Y. Cao, Chem. Mater., 2004, 16, 708-716.

20 H. Womelsdorf, W. Hoheisel and G. Passing, German Patent Specification 19907704 A1, filing date: 23.02.1999.

21 H. F. Dam and F. C. Krebs, Sol. Energy Mater. Sol. Cells, 2012, 97, 191-196.

22 J. E. Carlé, T. R. Andersen, M. Helgesen, E. Bundgaard, M. Jørgensen and F. C. Krebs, Sol. Energy Mater. Sol. Cells, 2013, 108, 126-128.

23 T. R. Andersen, H. F. Dam, B. Andreasen, M. Hösel, M. V. Madsen, S. A. Gevorgyan, R. R. Søndergaard, M. Jørgensen and F. C. Krebs, Sol. Energy Mater. Sol. Cells, 2014, 120, 735-743.

24 H. F. Dam, T. R. Andersen, E. B. L. Pedersen, K. T. S. Thydén, M. Helgesen, J. E. Carlé, P. S. Jørgensen, J. Reinhardt, R. R. Søndergaard, M. Jørgensen, E. Bundgaard, F. C. Krebs and J. W. Andreasen, Adv. Energy Mater., submitted.

25 A. P. L. Böttiger, M. Jørgensen, A. Menzel, F. C. Krebs and J. W. Andreasen, J. Mater. Chem., 2012, 22, 22501-22509.

26 F. C. Krebs and M. Jørgensen, Adv. Opt. Mater., 2014, 2, 465477.

27 M. O. Reese, S. A. Gevorgyan, M. Jørgensen, E. Bundgaard, S. R. Kurtz, D. S. Ginley, D. C. Olson, M. T. Lloyd, P. Morvillo, E. A. Katz, A. Elschner, O. Haillant, T. R. Currier, V. Shrotriya, M. Hermenau, M. Riede, 
K. R. Kirov, G. Trimmel, T. Rath, O. Inganäs, F. Zhang, M. Andersson, K. Tvingstedt, M. Lira-Cantu, D. Laird, C. McGuiness, S. Gowrisanker, M. Pannone, M. Xiao, J. Hauch, R. Steim, D. M. DeLongchamp, R. Rösch, H. Hoppe, N. Espinosa, A. Urbina, G. Yaman-Uzunoglu, J.-B. Bonekamp, A. J. J. M. van Breemen, C. Girotto, E. Voroshazi and F. C. Krebs, Sol. Energy Mater. Sol. Cells, 2011, 95, 1253-1267.

28 F. Machui, M. Hösel, N. Li, G. D. Spyropoulos, T. Ameri, R. R. Søndergaard, M. Jørgensen, A. Scheel, D. Gaiser,
K. Kreul, D. Lenssen, M. Legros, N. Lemaitre, M. Vilkman, M. Välimäki, S. Nordman, C. J. Brabec and F. C. Krebs, Energy Environ. Sci., 2014, DOI: 10.1039/c4ee01222d.

29 C. J. Mulligan, M. Wilson, G. Bryant, B. Vaughan, X. Zhou, W. J. Belcher and P. C. Dastoor, Sol. Energy Mater. Sol. Cells, 2014, 120, 9-17.

30 S. R. Dupont, M. Oliver, F. C. Krebs and R. H. Dauskardt, Sol. Energy Mater. Sol. Cells, 2012, 97, 171-175.

31 S. Savagatrup, A. D. Printz, D. Rodriquez and D. J. Lipomi, Macromolecules, 2014, 47, 1981-1992. 